\title{
Desenvolvimento da versão em português da Escala Administrada pelo Clínico para Avaliação de Mania (EACA-M): "Escala de Mania de Altman"
}

\author{
Flávio Shansis* \\ Marcelo T. Berlim** \\ Betina Mattevi*** \\ Gabriela Maldonado**** \\ Ivan Izquierdo***** \\ Marcelo Fleck ${ }^{\star \star \star \star * *}$
}

\section{INTRODUÇÃO}

Apesar da importante prevalência do Transtorno do Humor Bipolar (THB) (em torno de 1\% da população e de até 3 a $6 \%$ se utilizado o conceito de "espectro bipolar"1) e da grande morbi-mortalidade a ele associada, apenas seis instrumentos voltados para a avaliação do estado maníaco pelo clínico foram até hoje desenvolvidos ${ }^{2-7}$. Dentre esses instrumentos, a maioria apresenta limitações metodológicas que

\footnotetext{
Trabalho realizado nos Departamentos de Bioquímica e de Psiquiatria e Medicina Legal da UFRGS.

Agências de fomento: CAPES, FAPERGS e Propesq/UFRGS.

* Médico Psiquiatra do Serviço de Psiquiatria do Hospital de Clínicas de Porto Alegre (HCPA). Mestre em Bioquímica pela Universidade Federal do Rio Grande do Sul (UFRGS). Doutorando em Bioquímica (UFRGS).

** Médico, Aluno do Curso de Especialização em Psiquiatria do Departamento de Psiquiatria e Medicina Legal da UFRGS. Mestrando em Psiquiatria pela UFRGS.

*** Médica, Residente do Serviço de Psiquiatria do HCPA

**** Médica, Residente do Serviço de Dermatologia Sanitária da Secretaria da Saúde do estado do Rio Grande do Sul.

***** Professor Titular do Departamento de Bioquímica da UFRGS.

****** Professor Adjunto do Departamento de Psiquiatria e Medicina Legal da UFRGS
}

restringem sua utilidade clínica e diagnóstica ${ }^{8}$. Por exemplo, muitas destas escalas não foram testadas para várias qualidades psicométricas; o construto conceitual da maioria destes instrumentos baseia-se, em geral, apenas na clássica apresentação de mania eufórica, e os sintomas psicóticos são pouco valorizados. Em países de língua portuguesa, a situação é ainda mais problemática, na medida em que há apenas um instrumento de avaliação da mania validado que é a Escala de Mania de Young modificada para o português ${ }^{9}$. A escala de Young $^{5}$ foi criada em 1978 e é, ainda hoje em dia, a mais utilizada em ensaios clínicos que avaliam novas drogas anti-maníacas. Apesar de ser uma escala bastante fácil de ser usada, esta escala possui uma série de limitações metodológicas.

Dessa forma, os autores do presente estudo, desenvolveram a versão em português da "Clinician-Administered Rating Scale for Mania" (CARS-M) de Altman e colaboradores ${ }^{7}$, a fim de disponibilizar em nossa Língua mais um instrumento de avaliação do estado maníaco, além de ser a escala de mania mais recentemente elaborada. Ainda que esta escala tenha sido 
validada para a amostra de pacientes em que se originou, aguardam-se, a partir de agora, estudos testando a sua validade em nosso meio. A escala em português chamar-se-á Escala Administrada pelo Clínico para Avaliação de Mania (EACA-M) ou "Escala de Mania de Altman - Versão administrada pelo clínico". Dessa forma, os objetivos desse artigo são: (1) descrever a metodologia de elaboração da versão em português da CARS-M, (2) transmitir as impressões dos profissionais que a utilizaram e (3) disponibilizar a escala na íntegra em língua portuguesa (Anexo 1).

\section{MÉTODOS}

\section{Procedimentos para adaptação da CARS-M para ser utilizada em nosso meio}

Inicialmente, um grupo formado por 2 psiquiatras e 3 acadêmicos de medicina brasileiros traduziu, com permissão do autor principal, a escala original para o português. Em seguida, uma tradutora especializada fez a versão dessa escala do português para o inglês (back-translation). Essa versão em inglês foi, então, enviada para o primeiro autor da CARS-M (Edward Altman) para que ele a confrontasse com a escala original em inglês. As discrepâncias encontradas foram discutidas entre o autor e o grupo brasileiro com trocas de e-mails, a partir do que foi obtida a tradução definitiva para o português. Esse procedimento, abrangendo a um só tempo o conhecimento dos dois idiomas e do construto clínico de mania, favoreceu a obtenção de uma versão equivalente à original, tanto do ponto de vista da estrutura lingüística, quanto do ponto de vista do conteúdo semântico.

\section{Desenvolvimento da Versão Original em Inglês da Escala}

A escala descrita no presente artigo, intitulada "Clinician-Administered Rating Scale for Mania" (CARS-M) ${ }^{7}$, foi desenvolvida para ser aplicada na forma de uma entrevista semi-estruturada breve conduzida pelo clínico. A CARS$M$ investiga a presença versus a ausência de sintomas maníacos, sua severidade e sua mudança em resposta ao tratamento. Ela é derivada primariamente da "Schedule for Affective Disorders and Schizophrenia" (SADS) ${ }^{10}$ e contém 15 itens cuja pontuação, em seis graus, pode variar entre 0 (ausente) e 5 (extremo); um dos itens da escala ("insight") pode ser pontua- do entre 0 a 4 . Esses itens foram selecionados da SADS com base na sua habilidade em caracterizar a apresentação maníaca. Dentre estes, estão incluídos todos os sintomas maiores listados na definição de THB em fase maníaca do DSM-III-R ${ }^{11}$, além de itens que avaliam a presença de sintomas psicóticos como alucinações e delírios. Itens específicos para depressão e ansiedade foram excluídos de forma proposital, pois são provavelmente melhor avaliados por escalas específicas, como, por exemplo, pela Escala de depressão de Hamilton ${ }^{12}$. Por fim, diferentemente de muitas escalas, a maioria dos itens contém perguntas padronizadas que auxiliam o clínico na coleta das informações. A CARS-M é administrada, em geral, em 15 a 30 minutos, e sua pontuação contempla aspectos outros que não apenas os relatados pelo paciente ou observados pelo entrevistador (como, por exemplo, o comportamento do paciente observado pela equipe da Unidade de Internação, fora da entrevista). O período de tempo para a avaliação dos sintomas refere-se geralmente aos sete últimos dias, ainda que possa ser mais curto se for necessário para propósitos clínicos ou de investigação.

\section{Propriedades Psicométricas da Escala Original}

As informações apresentadas abaixo são oriundas do artigo de validação da versão original da EACA-M em inglês: CARS-M (para maiores detalhes vide Altman et al, 19947).

\section{A) Avaliação da Confiabilidade}

A.1) Confiabilidade Inter-avaliadores

A confiabilidade inter-avaliadores foi determinada a partir da pontuação - por parte de dois psiquiatras, um psicólogo e dois assistentes de pesquisa - de 14 entrevistas filmadas com pacientes portadores de diversos transtornos psiquiátricos (incluindo esquizofrenia $(n=3)$, depressão maior $(n=2)$, THB em fase maníaca $(n=8)$ e THB em fase depressiva $(n=1))$. Desses pacientes, oito eram do sexo masculino e seis do sexo feminino, sendo que sua idade variou de 18 a 49 anos. Todos eles haviam sido internados devido à agudização de seu quadro clínico, tendo sido entrevistados antes do início do tratamento.

O Coeficiente de Correlação Intraclasse (ICC) - que avalia a confiabilidade inter-valiadores - dos itens da CARS-M entre os cinco pontuadores para cada um dos 14 pacientes entrevistados variou de 0.54 a 0.99 , com uma média de 0.81 . O ICC da avaliação dos oito 
pacientes maníacos variou de 0.54 a 0.97 , com uma média de 0.80 . Além disso, foi investigada, entre os mesmos cinco pontuadores, a confiabilidade de cada um dos 15 itens individuais da CARS-M. A análise indicou uma excelente concordância entre os pontuadores para a grande maioria dos itens (variou de 0,66 a 0,94, com uma média de 0,83 ). Por fim, a ICC para os escores totais da CARS-M foi de 0.93. Esses resultados demonstram que a CARS-M apresenta uma excelente confiabilidade inter-avaliadores ${ }^{13}$.

\section{A.2) Confiabilidade Teste-Reteste}

A Confiabilidade teste-reteste foi determinada em uma outra amostra com 36 pacientes (16 pacientes bipolares e 20 não bipolares). Dois avaliadores pontuaram de forma independente estes pacientes logo após sua admissão e em dias separados (média de dois dias entre as duas pontuações).

Após a análise, a confiabilidade teste-reteste da CARS-M entre os pacientes bipolares $(n=16)$, utilizando-se o coeficiente de correlação de Pearson, foi, respectivamente, de 0.78 $(p<0.01)$ e $0.95(p<0.01)$ para o fator 1 (sintomas maníacos) e para o fator 2 (sintomas psicóticos) (ver adiante).

\section{B) Avaliação da Validade}

\section{B.1) Validade de Conteúdo}

A validade de conteúdo da CARS-M justifica-se por ela ser derivada da SADS (Schedule for Affective Disorders and Schizophrenia) ${ }^{10}$.

\section{B.2) Validade Concorrente de Construto}

A validade concorrente foi medida através do coeficiente de correlação de Pearson entre os escores totais da CARS-M e os da Young Mania Rating Scale (YMRS) ${ }^{5}$ em uma terceira amostra de 96 pacientes (sendo $24 \mathrm{com}$ esquizofrenia, 26 com depressão maior, 27 com THB em fase maníaca, $5 \mathrm{com}$ THB em episódio misto e 14 com transtorno esquizoafetivo). A correlação entre os escores foi de 0.94 , indicando que a CARS-M apresenta excelente validade concorrente.

B.3) Análise dos Componentes Principais

A análise dos compontes principais, na amostra dos 96 pacientes anteriormente citados, revelou a presença de dois fatores proeminentes na CARS-M que foram responsáveis por $49 \%$ da variância total. O primeiro deles, identificado como fator "mania", consiste dos itens 1 a 10 e avalia sintomas classicamente manía- se", consiste dos itens 11 a 15 e avalia sintomas predominantemente psicóticos.

Diferentemente de todas as outras escalas de mania, a análise estatística da CARS-M possibilitou gerar os seguintes pontos de corte para os escores do Fator 1 ("mania"): 0-7, mania questionável ou ausente; 8-15, mania leve; 1625 , mania moderada; e 26 ou mais, sintomas maníacos severos. Isto permite ao clínico um aproximação mais objetiva no sentido de quantificar a apresentação sintomatológica de determinado paciente.

Cabe ressaltar que os dois fatores obtêm pontuações diferenciadas: uma pontuação para mania (Fator 1) e outra para psicose (Fator 2). Estas pontuações são independentes e, ainda que se possa somá-las para se obter um fator geral de mania, não é aconselhado realizar esta soma, tanto do ponto de vista psicométrico, quanto do clínico ${ }^{14}$.

\section{B.4) Consistência Interna}

Os coeficientes $\propto$ de Cronbach dos dois fatores da CARS-M foram, respectivamente 0.88 (fator 1) e 0.63 (fator 2), indicando excelente confiabilidade para o fator "mania" e confiabilidade regular para o fator "psicose".

\section{Impressão dos profissionais que utilizaram a EACA-M}

A versão em português da Escala Administrada pelo Clínico para Avaliação de Mania (EACA-M) mostrou ser este um intrumento bastante fácil e objetivo de ser utilizado. As "âncoras" explicativas que existem em cada item proporcionam uma segurança maior ao entrevistador, o que não ocorre na grande maioria de escalas existentes em psiquiatria. Estas explicações aparecem tanto como definições conceituais ao lado do título de cada item, como também aparecem na forma de exemplos em cada um dos níveis de severidade. Isto facilita enormemente a tarefa de pontuação. Ao final de cada item, há perguntas ou orientações que, além de serem extremamente úteis, tornam mais objetiva a entrevista com o paciente e permitem uma maior homogeinização na inquisição e aferição dos sintomas. Ainda, a divisão da avaliação em sintomas mais caracteristicamente maníacos distintos dos ditos sintomas psicóticos, possibilita uma visão psicopatológica mais rica e definida da apresentação de uma síndrome maníaca. Finalmente, a soma dos escores totais do Fator 1 em mania questionável, leve, moderada e severa permite ao avaliador confrontar a sua impressão clínica com uma 
medida mais objetiva. Por tudo isso, os profissionais que utilizamos a EACA-M neste primeiro momento percebemos esta escala como sendo um instrumento com muito bom potencial, de fácil manejo e que possibilita uma ampla avaliação de um quadro maníaco. Resultados objetivos das qualidades psicométricas da versão em português da EACA-M serão objeto de futuras publicações.

\section{Adaptação da CARS-M para outras línguas}

Existe apenas um único estudo de adaptação da escala para outra língua que não a lingua inglesa original. Foi realizado um estudo na Espanha ${ }^{14}$, de adaptação da CARS-M para o espanhol, no qual foram utilizados 24 pacientes (9 homens e 15 mulheres), sendo 19 internados e 13 ambulatoriais, em um total de 81 entrevistas. Neste estudo, a consistência interna da subescala de mania (Fator 1), medida pelo coeficiente $\propto$ de Cronbach, foi bastante alta, de 0,91 (variando entre os diferentes itens entre 0,49 a 0,78). Já a confiabilidade inter-avaliadores avaliada pelo Coeficiente de Correlação Intra-Classe (ICC) desta subescala de mania, foi de 0,94 (variando entre os diferentes itens entre 0,77 a 0,93), e de 0,90 (variando entre 0,55 e 0,95$)$ para a subescala de psicose (Fator 2). Estes resultados são considerados bastante satisfatórios e praticamente os mesmos do artigo original $^{7}$. Este artigo em espanhol, entretanto, não realiza uma análise dos componentes principais e baseia toda a sua avaliação psicométrica no resultado da análise dos componentes principais do artigo original (que encontrou o Fator 1 de "mania" e o Fator 2 de "psicose"), comparando resultados nestas duas prováveis subescalas. Apesar de os colegas espanhóis ${ }^{14}$ produzirem um artigo consistente, é temerário analisar os dados simplesmente replicando uma possível estrutura (mas não comprovada por mais estudos) desta escala, a partir da análise original dos componentes principais, na qual ela possuiría as duas subescalas de mania e de psicose. De qualquer forma, é interessante observar os bons resultados que a versão em espanhol apresenta.

\section{DISCUSSÃO}

A escala de mania de Altman e colaboradores (CARS-M $)^{7}$ representa um avanço em relação às demais escalas que avaliam o estado maníaco. Isto se dá não apenas por ela ser a escala mais recentemente elaborada mas, e principalmente, pela forma como foi concebida e avaliada. Desta forma, a CARS-M é considerada como sendo o intrumento de avaliação do estado maníaco com as melhores propriedades psicométricas citadas até os dias de hoje ${ }^{14}$. Diferentemente da escala de Young ${ }^{5}$, que é hoje considerada a escala "padrão" em estudos com pacientes bipolares (em especial, em estudos que envolvam comparação entre drogas), a CARS-M preencheu desde sua elaboração uma série de pré-requistos que hoje são exigidos quando da criação de uma nova escala. A começar pela sua validação de conteúdo, que se deriva de um instrumento já reconhecido pela comunidade científica: o $\operatorname{SADS}^{10}$. O conteúdo que originou a escala de Young $^{5}$ derivou de revisão da literatura e da experiência clínica dos autores no ano de 1978. Em função disso, esta última escala apresenta falhas na avaliação de sintomas tão importantes em apresentações maníacas, como os sintomas psicóticos, por exemplo, que são pontuados em apenas um dos 11 itens da escala. Além disso, a escala de Young ${ }^{5}$ faz uma escolha absolutamente arbitrária de três itens que recebem pontuação maior do que os oito restantes. Em relação à confiabilidade inter-avaliadores, a CARS-M apresenta resultados bem consistentes, utilizando-se do Coeficiente de Correlação Intraclasse (ICC), que é hoje considerado o melhor padrão de mensuração desta qualidade psicométrica. Já a escala de Young, na sua versão original, avaliou esta confiabilidade através de outros parâmetros não mais aceitos como tão adequados hoje em dia. Por outro lado, foi realizado em nosso meio um estudo de validação desta escala muito bem conduzido por Vilela e Loureiro ${ }^{9}$. Este estudo brasileiro empregou o ICC para avaliar este aspecto e demonstrou excelente confiabilidade inter-avaliadores. Em relação à avaliação de sua validade, a CARS-M apresenta excelentes resultados quando são avaliadas a sua consistência interna e validação concorrente, assim como apresenta uma análise dos componentes principais bastante interessante com dois fatores diversos. É a primeira escala de avaliação de mania que, a partir da análise dos componentes principais, apresenta dois fatores distintos clinicamente importantes: o fator de sintomas classicamente maníacos e o fator com sintomas psicóticos. Isto é particularmente importante quando se valoriza cada vez mais a complexidade das diversas apresentações no THB, assim como também é importante na distinção entre os efeitos antimaníacos e/ou antipsicóticos de novas drogas que vêm sendo testadas no THB (como, 
por exemplo, os antipsicóticos atípicos). O trabalho original da escala de Young ${ }^{5}$ não realizou uma análise dos componentes principais, tarefa esta que foi realizada por nossos colegas brasileiros quando da validação deste instrumento em nosso meio ${ }^{9}$. Entretanto, alguns trabalhos de análise dos componentes principais com a escala de Young, realizados nos últimos anos $^{15,16}$, têm divergido em seus resultados.

Entretanto, apesar do avanço que a CARS$M$ representa em relação às escalas anteriormente criadas e dos cuidados na sua elaboração, alguns pontos merecem críticas. Primeiro, dos 14 pacientes no estudo inicial da confiabilidade inter-avaliadores, apenas 8 eram efetivamente maníacos. Segundo, dos 36 pacientes descritos nos segundo estudo de confiabilidade teste-reteste, apenas 16 eram bipolares. Terceiro, na amostra de 96 pacientes a partir da qual foram realizadas a validade concorrente, a análise dos componentes principais e a consistência interna, apenas 27 eram pacientes bipolares em fase maníaca. Estudos com amostras maiores são esperados. Apesar destas críticas (em especial no que diz respeito à pouca representação relativa de pacientes maníacos nas amostras estudadas), a concepção da escala e a avaliação criteriosa de sua qualidades psicométricas tornam esta escala - do ponto de vista teórico - a escala de mania melhor elaborada até agora. Quando ela foi comparada à escala de Young, no artigo que a originou, a mesma apresentou resultados bastante semelhantes na avaliação de pacientes maníacos ${ }^{7}$. Mais estudos, portanto, comparando a CARS-M a outras escalas de mania são aguardados para confirmar ou não, em diferentes amostras, as suas qualidades psicométricas.

Em relação a sua versão em português - a EACA-M - todos os cuidados foram tomados para que a mesma mantivesse em outra língua as suas características originais, tanto do ponto de vista da estrutura lingüística, quanto do ponto de vista do conteúdo semântico. Para tanto, os autores do presente artigo preocuparam-se em realizar todas as etapas necessárias para este fim, a saber: a) painel bilíngüe de tradução e discussão de todos os itens; b) retrotradução por pessoa habilitada e com larga experiência em versões de escalas em nosso meio; c) envio ao próprio autor da escala da nova versão em inglês originada a partir da sua tradução para o português; d) discussão com o autor dos pontos pendentes bem como nova discussão entre os participantes do grupo de pesquisadores brasileiros até se chegar a um consenso. bastante fácil pelos avaliadores brasileiros. As "âncoras explicativas" permitem definir claramente o que a escala pretende avaliar em cada item, tornando, com isso, o trabalho de avaliação mais criterioso. Por fim, os pontos de corte apresentados pela escala (sem mania, mania leve, moderada e severa) auxiliam o investigador a comparar a sua impressão clínica com uma medida mais objetiva. Com isso, entendese que a versão que agora está sendo disponibilizada à comunidade científica de língua portuguesa é a mais próxima possível da escala original.

\section{CONCLUSÕES}

Sendo o THB um transtorno prevalente, urge a elaboração e a disponibilização de instrumentos que possam melhor avaliar a apresentação maníaca, da mesma forma como já existem alguns instrumentos para avaliação da depressão. Em nosso meio, temos apenas a versão já validada em português da escala de Young modificada (EAM-m) ${ }^{9}$. Ainda que esta seja a escala mais amplamente utilizada em ensaios clínicos, algumas críticas sobre ela vêm gradativamente ocorrendo na comunidade científica, em especial sobre a validade de seu conteúdo em relação à complexidade das apresentações de uma síndrome maníaca e à falta de mais trabalhos avaliando as suas propriedades psicométricas. Neste sentido, o surgimento de novas escalas para avaliação do estado maníaco, em especial com maior rigor metodológico - tanto na sua elaboração, quanto na avaliação de seus parâmetros psicométricos é sempre bem-vindo. A CARS-M preenche muitos destes critérios. A sua versão em português - denominada de EACA-M - vem, portanto, preencher este espaço na comunidade científica de língua portuguesa a partir de uma versão bem cuidada e com a anuência do próprio autor da escala original. Desta forma, os autores do presente trabalho esperam estar disponibilizado uma nova escala de mania em português, que apresenta robustez nas suas qualidades psicométricas em sua versão original em inglês. Aguardam-se estudos em nosso meio testando se estas qualidades psicométricas confirmar-se-ão ou não em português. Finalmente, os autores do presente artigo esperam que a mesma possa ser utilizada em nosso meio, tanto na comunidade acadêmica para fins de pesquisa, quanto na clínica psiquiátrica, servindo como mais um instrumento a melhor guiar a prática diária do clínico que lida no cotidiano com pacientes maníacos. 


\section{REFERÊNCIAS BIBLIOGRÁFICAS}

1. Akiskal HS. The prevalent clinical spectrum of bipolar disorders: beyond DSM-IV. J Clin Psychopharmacol 1996; 16: 4S-14S.

2. Petterson U, Fyro B, Sedvall G. A new scale for the longitudinal rating of manic states. Acta Psychiatrica Scand 1973; 49: 248-256.

3. Blackburn I, Loudon J, Ashworth C. A new scale for measuring mania. Psychol Medicine 1977; 7: 453-458.

4. Bech P, Rafaelsen O, Kramp P, Bolwig T. The mania rating scale: scale construction and inter-observer agreement. Neuropharmacology 1978; 17: 430-431.

5. Young R, Biggs J, Ziegler V, Meyer D. A rating scale for mania: reliability, validity and sensivity. British J Psychiatry, 1978; 133: 429-435.

6. Secunda S, Katz M, Swann A, Koslow S. Mania. Diagnosis, state measurement and prediction of treatment response. J Affect Disorders 1985; 8: 113-121.

7. Altman EG, Hedeker DR, Janicak PG, Peterson JL, Davis JM. The Clinician-Administered Rating Scale For Mania (CARS-M): Development, reliability, and validity. Biol Psychiatry 1994; 36:124-34.

8. Poolsup, N, Li Wan, A, Oyebode, F. Measuring mania and critical appraisal of rating scale. J Clin Pharmacy and Therapeutics 1999; 24: 433-443.

9. Vilela J, Loureiro S. Escala de Avaliação de Mania de Young - Estudo das qualidades psicométricas da versão brasileira. In: Gorentsein C, Andrade L, Zuardi A., editores. Escalas de Avaliação Clínica em Psiquiatria e Psicofarmacologia. São Paulo: Lemos Editorial; 2000. p. 11323.

10. Endicott J, Spitzer R. A diagnostic interview. The Schedule for Affective Disorder and Schizophrenia. Arch Gen Psychiatry 1978; 35: 837-844.

11. American Psychiatric Association. Diagnostic and statistical manual of mental disorders, $3^{\text {rd }}$ revised (DSM-III -R). Washington DC: American Psychiatric Association; 1990.

12. Hamilton, M. A rating scale for depression. J Neurol Neurosurg 1960; 23: 56-62.

13. Fleiss JL. Statistical Methods for Rates and Proportions. $2^{\text {nd }}$ ed. New York: Wiley \& Sons $; 1981$.

14. Livianos L, Rojo L, Guillem J, Pino A, Mora R, Vila M, Domínguez A Adaptación de la Escala para la Valoración de la Manía por Clínicos (EVMAC). Actas Esp Psiquiatr 2000; 28 (3): 169-77.

15. Double D. The factor structure of manic rating scales. J Affect Disorders 1990; 18: 113-19.

16. Youngstrom E, Danielson C, Findling R, Garcious B, Calabrese J. Factor structure of the Young Mania Rating Scale for use with youths ages 5 to 17 years. J Clin Child and Adolescent Psychology, 2002; 4: 567-72.

\section{RESUMO}

Objetivos: No presente artigo é apresentado o desenvolvimento da versão em português da "Clinician-Administered Rating Scale for Mania" (CARS-M) de Altman e colaboradores intitulada: Escala Administrada pelo Clínico para Avaliação de Mania (EACAM) ou "Escala de Mania de Altman". Os objetivos desse artigo são: (1) descrever a metodologia de elaboração da versão em português da CARS-M, (2) transmitir as impressões dos profissionais que a utilizaram e (3) disponibilizar a escala na íntegra em língua portuguesa. Métodos: Os métodos utilizados foram: a) painel bilíngüe de tradução e discussão de todos os itens; b) retrotradução por pessoa habilitada; c) envio ao próprio autor da escala da nova versão em inglês originada a partir da sua tradução para o português; d) discussão com o autor dos pontos pendentes, bem como nova discussão entre os participantes do grupo de pesquisadores brasileiros até se chegar a um consenso. Conclusões: $A$ impressão dos autores é a de que a EACA-M permite não apenas a fácil pontuação de todos os escores, mas também cobre o largo espectro de apresentação de uma síndrome maníaca. Com este artigo, a comunidade científica de Língua Portuguesa passa a dispor de um importante instrumento para avaliação do estado maníaco.

Descritores: Escalas de avaliação, mania, transtorno de humor bipolar.

\section{ABSTRACT}

Objectives: The following article presents the development of the Portuguese-language version of the "Clinician-Administered Rating Scale for Mania" (CARS-M) by Altman and collaborators. The objectives of the article are: 1. to describe the methodology used to prepare the Portugueselanguage version of CARS-M 2. to transmit the impressions of professionals who have worked with it, and 3. to make the whole scale available in the Portuguese language. Methods: The methods used were: a. bilingual panel to translate and discuss all items; b. a backtranslation by an able person; $c$. sending the author the new English version of the scale in its new English version developed from its translation into Portuguese and $d$. discussing the pending points with the author, and a new discussion among the members of the Brazilian group of researchers until they achieve a consensus. Conclusions: The authors' impression is that the EACA-M not only makes it easy to establish all scores, it also covers the broad spectrum of presentation of a maniac syndrome. With this article, the Portuguese-language scientific community will have a major instrument to evaluate a maniac state.

Key-words: Bipolar disorders, mania, rating scales.

Title: Development of the Portuguese-language versión of the Clinician-Administered Rating Scale for Mania (CARS-M): "Altman Scale for Mania"

\section{RESUMEN}

Objetivos: En el siguiente artículo se presenta el desarrollo de la versión en portugués de la "ClinicianAdministered Rating Scale for Mania" (CARS-M) de Altman y sus colaboradores titulada: "Escala Administrada por el Clínico para la Evaluación de Manía" (EACA-M), o "Escala de Altman". Los objetivos de 
este artículo son: 1) describir la metodología de elaboración de la versión en portugués de la CARS-M. 2) transmitir las impresiones de los profesionales que la utilizaron. 3) disponibilizar la escala en su íntegra, en lengua portuguesa. Métodos: los métodos utilizados son: a) panel bilingüe de traducción y discusión de todos los ítems; b) retro traducción por una persona habilitada; c) envío, al propio autor de la escala, de la nueva versión en inglés, originada a partir de su traducción al portugués y d) discusión con el autor, sobre los puntos pendientes, así como una nueva discusión entre los participantes del grupo de investigadores brasileños, hasta llegar a un consenso. Conclusiones: la impresión de los autores, es de que la EACA-M, permite no sólo la fácil puntuación de todos los escores, así como también cubre, el largo espectro de presentación de un síndrome maníaco. Con este artículo, la comunidad científica de lengua portuguesa, pasa a disponer de un importante instru- mento para la evaluación del estado maníaco.

Palabras-clave: Escalas de evaluación; manía; trastorno de humor bipolar.

Título: Desarrollo de la versión para Portugués de la Escala Administrativa por el Clínico para Avaluación de Manía (EACA - M): "Escala de Manía de Altman"

Endereço para correspondência:

Flávio Shansis

Avenida Taquara, 586/606

90460-210 - Porto Alegre - RS

E-mail: shansis.ez@terra.com.br

Copyright (c) Revista de Psiquiatria do Rio Grande do Sul - SPRS 
Anexo 1: Escala Administrada pelo Clínico para Avaliação de Mania (EACA-M) (Altman e cols, 1994): versão em português Adaptação: Shansis F, Berlim M, Mattevi B, Maldonado G, Izquierdo I, Fleck M.

Paciente:

Data: Avaliador:

Fator 1 (item 1-10):

Fator 2 (item 11-15):

Pontuação total:

Nota: Para completar esta escala, as informações devem ser obtidas não apenas a partir da entrevista com o paciente, mas também de outras fontes confiáveis, incluindo familiares, equipe de enfermagem, registros hospitalares, etc. Em geral, o período de tempo para a aferição dos sintomas deve ser o dos últimos 7 dias, podendo ser mais longo quando for necessário.

1. Humor Elevado/Eufórico (Otimismo inapropriado relacionado com o presente ou com o futuro, que tenha se mantido por pelo menos várias horas e que tenha sido desproporcional às circunstâncias).

0 Ausente

1 Discreto, por exemplo, animado, mais alegre do que os outros, de questionável significância clínica.

2 Leve, mas com o humor definidamente elevado ou expansivo, excessivamente otimista e relativamente desproporcional às circunstâncias.

3 Moderado, humor e "visão de mundo" claramente desproporcionais às circunstâncias.

4 Severo, humor claramente eufórico.

5 Extremo, claramente exaurido, sentimentos extremos de bem-estar, riso inapropriado e/ou cantando.

- Houve momentos, na última semana ou mês, em que você se sentiu estranhamente bem, alegre ou feliz?

- Você sentiu como que se todas as coisas fossem se realizar exatamente da maneira como você queria?

- Isso difere de seu humor normal? Quanto tempo durou?

2. Irritabilidade/Agressividade (O paciente demonstrou, recentemente, tanto na entrevista quanto fora dela, expressão evidente de raiva, irritabilidade ou aborrecimento. Não incluir meros sentimentos subjetivos de raiva/aborrecimento, a menos que sejam expressados abertamente).

0 Ausente

1 Discreta, aborrecimento ocasional, de questionável significância clínica.

2 Leve, relativamente argumentativo, expressa prontamente aborrecimento com pacientes, equipe ou entrevistador, ocasionalmente irritado durante a entrevista.

3 Moderada, freqüentemente pragueja, perde a calma, ameaça, irrita-se excessivamente com alguns tópicos, isolamento pode ser necessário, freqüentemente irritável durante a entrevista.

4 Severa, ocasionalmente agressivo, pode arremessar objetos, danificar bens, é necessário impor limites, irritação inapropriada ou excessiva, contenção pode ser necessária, a entrevista tem de ser interrompida devido a excessiva irritabilidade.

5 Extrema, episódios de violência contra as pessoas ou objetos, contenção física é necessária.

- Como você tem lidado, em geral, com as pessoas?

- Você tem se sentido irritável ou raivoso? O quanto do seu dia você se sente assim?

- Você se envolveu mais do que o usual em discussões ou brigas? Com que freqüência? 
3. Atividade Hipermotora (Demonstrou, recentemente, tanto na entrevista quanto fora dela, manifestações visíveis de hiperatividade motora generalizada. Não incluir meros sentimentos subjetivos de inquietação não relacionados à medicação).

0 Ausente

1 Discreto aumento, de duvidosa significância clínica.

2 Leve, caminha ocasionalmente, incapaz de sentar calmamente na cadeira.

3 Moderada, caminha com freqüencia na Unidade, incapaz de ficar sentado.

4 Marcada, movimentando-se ou caminhando de forma quase constante.

5 Extrema, sinais contínuos de hiperatividade, tal que o paciente precisa ser contido para evitar exaustão.

- Houve momentos nos quais você era incapaz de ficar sentado ou momentos em que você teve que ficar se movimentando ou dando passos para trás e para a frente?

4. Pressão para Falar (Quantidade e ritmo de discurso aumentado, acelerado ou premente, tanto na entrevista quanto fora dela).

0 Ausente

1 Discreto aumento, de duvidosa significância clínica.

2 Leve, notadamente mais verborréico do que o normal, mas a conversação não é difícil.

3 Moderada, tão verborréico que a conversação é difícil; alguma dificuldade para interromper o discurso do paciente.

4 Marcada, a conversação do paciente é tão rápida que é difícil mantê-la, marcadamente difícil interromper o discurso.

5 Extrema, o discurso é tão rápido ou contínuo que o paciente não pode ser interrompido.

5. Fuga de Idéias/Pensamentos Acelerados (Discurso acelerado com mudanças abruptas de tópico para tópico, usualmente baseado em associações compreensíveis, estímulos distrativos ou jogos de palavras. Quando severa, as associações podem ser tão difíceis de entender que frouxidão de associação ou incoerência também podem estar presentes. Aceleração de pensamento refere-se ao relato subjetivo do paciente quanto a estar tendo pensamentos rápidos dentro de sua mente).

0 Ausente

1 Discreta, episódios ocasionais de duvidosa significância clínica.

2 Leve, episódios ocasionais de mudança abrupta de tópico com pequeno prejuízo na compreensibilidade ou paciente relata pensamentos acelerados ocasionais.

3 Moderada, episódios freqüentes com algum prejuízo na compreensibilidade, ou o paciente relata pensamentos acelerados freqüentes que são disruptivos ou aflitivos.

4 Severa, episódios muito freqüentes com prejuízo definido.

5 Extrema, a maior parte do discurso consiste de rápidas mudanças de tópico que são difíceis de acompanhar.

- Você se sentiu incomodado por ter muitos pensamentos de uma só vez?

- Você teve pensamentos acelerados dentre de sua mente? Com que freqüência? Isso impediu seu funcionamento?

6. Distração (A atenção é muito facilmente direcionada para estímulos externos não importantes ou irrelevantes; i.e., barulho de uma sala contígua, livros numa prateleira, roupas do entrevistador, etc. Excluir distração devida a intrusões de alucinações visuais e/ou auditivas ou delírios. Pontue baseado apenas na observação). 
0 Ausente

1 Discreta, de duvidosa significância clínica.

2 Leve, presente, mas não interfere na tarefa ou na conversação.

3 Moderada, alguma interferência na conversação ou na tarefa.

4 Severa, freqüente interferência na conversação ou na tarefa.

5 Extrema, impossível direcionar a atenção do paciente para uma tarefa ou conversação.

7. Grandiosidade (Auto-estima aumentada e avaliação não realista ou inapropriada do valor, importância, poder, conhecimento ou habilidade pessoal).

0 Ausente.

1 Auto-estima ou confiança discretamente aumentada, mas de questionável significância clínica.

2 Leve, auto-estima definidamente inflada ou percepção exagerada das habilidades relativamente desproporcional às circunstâncias.

3 Moderada, auto-estima inflada claramente desproporcional às circunstâncias, idéias de intensidade delirante fronteiriça.

4 Severa, delírios de grandeza definidos.

5 Extrema, absorto em delírios de grandeza.

- Você se sentiu mais auto-confiante do que o usual?

- Você sentiu que era uma pessoa particularmente importante ou que você tinha poderes especiais, conhecimento ou habilidades fora do comum?

- Há alguma missão ou propósito especial para sua vida?

- Você tem alguma relação especial com Deus?

8. Necessidade Diminuída de Sono (Menor necessidade de sono do que o usual para sentir-se descansado. Não pontue dificuldade na forma de insônia inicial, intermediária ou tardia).

0 Ausente

1 Até 1 hora a menos de sono do que o usual.

2 Até 2 horas a menos de sono do que o usual.

3 Até 3 horas a menos de sono do que o usual.

4 Até 4 horas a menos de sono do que o usual.

5 Quatro ou mais horas a menos de sono do que o usual.

- Quanto tempo você precisa dormir normalmente?

- Você vem necessitando dormir menos do que o usual para se sentir descansado?

- Quanto tempo a menos de sono você precisa/precisou?

9. Energia Excessiva (Com energia incomum ou mais ativo do que o usual sem a esperada fadiga, durando pelo menos vários dias).

0 Ausente.

1 Discretamente com mais energia, de questionável significância.

2 Aumento definido no nível de atividade ou menos fatigado do que o usual, não atrapalha o funcionamento.

3 Claramente mais ativo do que o usual com pouca ou nenhuma fadiga, interferência ocasional no funcionamento.

4 Muito mais ativo do que o usual com pouca fadiga e clara interferência no funcionamento normal.

5 Extrema, ativo durante todo o dia com pouca ou nenhuma fadiga ou necessidade de dormir. 
- Você teve mais energia do que o usual para fazer as coisas?

- Você tem sido mais ativo do que o usual ou teve o sentimento de que você poderia funcionar por todo o dia sem se sentir cansado?

10. Julgamento Empobrecido (Excessivo envolvimento em atividades sem o reconhecimento do grande potencial de conseqüências dolorosas; intromissão, chamando inapropriadamente a atenção para si próprio).

0 Ausente.

1 Discreto, mas de questionável significância clínica (i.e., aumento de chamadas telefônicas, intromissão ocasional).

2 Leve, mas exemplos definidos (i.e., relativamente intrometido, sexualmente provocativo, cantando inapropriadamente).

3 Moderado, assume tarefas ou responsabilidades sem o treinamento apropriado, imprudências financeiras, gastando dinheiro além dos seus limites financeiros ou da necessidade, intromissão freqüente.

4 Severo, promiscuidade sexual, hipersexualidade, comportamento extremamente intrometido, coloca-se em dificuldades econômicas significativas.

5 Extremo, comportamento intrometido contínuo requerendo imposição de limites, excessivas chamadas telefônicas a toda hora, comportamento antisocial, envolvimento excessivo em atividades, desconsiderando as conseqüências.

- Quando você estava se sentindo eufórico ou irritável, você fez coisas que causaram problemas para você ou sua família?

- Você gastou dinheiro inconseqüentemente?

- Você assumiu responsabilidades para as quais você não era qualificado?

11. Transtorno de Pensamento (Pensamentos do paciente com prejuízo na capacidade de compreeensão como manifestado pela sua fala. Isto pode ser devido a um ou a uma combinação dos seguintes fatores: incoerência, frouxidão de associação(ões), neologismos, pensamento ilógico. Não pontue fuga de idéias, a menos que seja severa).

0 Ausente.

1 Situações ocasionais que são de questionável significância clínica.

2 Algumas situações definidas, mas pouco em nenhum prejuízo na compreensão.

3 Situações freqüentes e pode haver algum prejuízo na compreensão.

4 Severo, situações muito freqüentes com marcado prejuízo na compreensão.

5 Extremo, a maioria ou toda a fala está distorcida, tornando impossível compreender sobre o que o paciente está falando.

12. Delírios (Crenças falsas fixas, variando desde idéias delirantes a delírios completos - incluindo grandiosidade).

Especifique o tipo:

Determine se humor-congruente: ou humor-incongruente:

0 Ausente.

1 Suspeito ou provável.

2 Definitivamente presente, mas não completamente convicto, incluindo idéias de referência ou persecutórias sem absoluta convicção. 
3 Definitivamente presente com completa convicção, mas pouca, se existe alguma, influência no comportamento.

4 O delírio possui um efeito significativo sobre os pensamentos, sentimentos ou comportamento do paciente ( p.ex., preocupado com a crença de que os outros estão tentando prejudicá-lo).

5 Ações baseadas em delírios possuem importante impacto sobre o paciente ou os outros (p.ex., parar de se alimentar devido à crença de que a comida está envenenada, bater em alguém devido à crença de que os outros o estão prejudicando).

- Você sentiu que alguém estava tentando lhe prejudicar ou lhe machucar sem razão? Você pode dar um exemplo?

- Você sentiu como se você estivesse sendo controlado por uma força ou um poder externo? (Exemplo?)

- Você sentiu como se as pessoas no rádio ou na televisão estivessem falando para você, sobre você, ou se comunicando com você de alguma forma especial? (Exemplo).

- Você teve alguma (outra) crença ou idéia estranha ou não usual?

- Estas crenças interferiram com o seu funcionamento de alguma maneira?

13. Alucinações (Uma percepção sensorial sem estimulação externa em relevante órgão sensorial).

Especifique o tipo:

Determine se humor-congruente: ou humor-incongruente:

0 Ausente

1 Suspeito ou provável.

2 Presente, mas o sujeito está geralmente consciente de que isto se deve a sua imaginação e pode ignorá-la.

3 Definitivamente presente com completa convicção, mas pouca, se existe alguma, influência no comportamento.

4 As alucinações possuem efeito significativo sobre os pensamentos, sentimentos ou ações do paciente (p.ex., trancar as portas para evitar perseguidores imaginários).

5 As ações baseadas em alucinações possuem importante impacto no paciente e nos outros (p.ex., o paciente conversa tanto com as vozes que isto interfere com o seu funcionamento normal).

- Você ouviu sons ou vozes de pessoas falando quando não havia ninguém ao redor? (Exemplo.)

- Você enxergou algumas visões ou sentiu alguns odores que os outros não perceberam? (Exemplo.)

- Você teve algumas (outras) percepções estranhas ou não usuais?

- Estas experiências interferiram com o seu funcionamento de alguma forma?

14. Orientação ( Prejuízo na memória recente ou remota, ou desorientação quanto a pessoas, lugares ou tempo).

0 Ausente

1 Discreto prejuízo, mas de questionável significância clínica (p.ex. esquece datas.)

2 Leve, mas prejuízo definido (p.ex, inseguro quanto à orientação de tempo e espaço, ou algum prejuízo em poucos aspectos da memória recente ou remota).

3 Moderada ( p.ex, confuso sobre onde ele (a) está ou não consegue se lembrar de eventos muito importantes da sua vida).

4 Severa ( Desorientado ou grave prejuízo na memória). 
5 Extrema ( p.ex, completamente desorientado quanto ao tempo, espaço, pessoas e/ou é incapaz de recordar numerosos eventos importantes da sua vida).

- Você teve recentemente problemas em se lembrar de quem você era, datas ou de eventos atuais?

- Você sabe o dia da semana, o mês, o ano e o nome deste lugar?

15. Insight (Dimensão na qual o paciente demonstra uma consciência ou entendimento de sua doença emocional, comportamento aberrante e/ou uma necessidade correspondente por tratamento psiquiátrico/psicológico.)

0 Insight está presente (p.ex, o paciente admite doença, mudança de comportamento ou necessidade de tratamento.)

1 Insight parcial está presente (p.ex, o paciente sente que ele (a) possa possivelmente estar doente ou necessitando de tratamento, mas não está seguro disso.)

2 O paciente admite mudança de comportamento, doença ou necessidade de tratamento, mas atribui isso a fatores externos plausíveis ou não-delirantes ( p.ex, conflito marital, dificuldades no trabalho, estresse.)

3 O paciente admite mudança de comportamento, doença ou necessidade de tratamento, mas dá explicações delirantes (p.ex, está sendo controlado por forças externas, morrendo de câncer, etc.)

4 Falta completa de insight. O paciente nega mudança de comportamento, doença ou necessidade de tratamento.

- Você sente que atualmente sofre de problemas emocionais ou psicológicos de algum tipo?

- Como você explicaria o seu comportamento ou sintomas?

- Você atualmente acredita que precisa de tratamento psiquiátrico?

\section{Soma dos itens do Fator 1:}

0-7 = Nenhuma ou questionável mania

8-15 = Mania leve

16-25 = Mania moderada

26 ou mais = Sintomas maníacos severos 
Anúncio Bristol página 425 